\title{
Co-design de Groupware para Planejamento entre Professores do Ensino Médio
}

\author{
Leandro Marques Queiros, Alex Sandro Gomes \\ ${ }^{1}$ Centro de Informática (CIn) - Universidade Federal de Pernambuco (UFPE) \\ Caixa Postal 7851 - 50740-560 - Recife - PE - Brasil \\ \{lmq, asg\}@ein.ufpe.br
}

\begin{abstract}
Educational planning, and consequently, the production of educational materials, are considered essential for teachers. These artifacts are commonly adapted, improvised, or copied and pasted from the planning used in the previous year to meet a school standard. This paper aims to contribute to a better understanding of teachers' planning practices, to influence the design of groupware-supported learning experience to be integrated into teaching practice, to promote the effective development of collaborative class planning.
\end{abstract}

Resumo. O planejamento educacional e, consequentemente, a produção de materiais educativos são considerados essenciais para os professores. Esses artefatos são comumente adaptados, improvisados, ou copiados e colados do planejamento utilizado no ano anterior, para cumprir um padrão escolar. O presente trabalho visa contribuir para uma melhor compreensão das práticas de planejamento dos professores, para influenciar no design da experiência de aprendizagem apoiada por groupware para ser integrado na prática de ensino, a fim de promover o desenvolvimento efetivo do planejamento colaborativo de aula.

\section{O planejamento colaborativo de aula efetivo}

Há três principais problemas relacionados à atividade de planejamento de aula: falta de tempo, o que leva ao estresse do professor; falta de apoio para compartilhar planos de aula com outros colegas professores; e cultura de isolamento no planejamento do plano de aula [Rossitto and Lampinen 2018]. Considerando os problemas supramencionados, o planejamento colaborativo de aula tem se tornando relevante em pesquisas na área de Aprendizagem Aprimorada por Tecnologia, pois estas pontecializam o ensino-aprendizagem [Nguyen and Bower 2018].

O desafio no contexto brasileiro está baseado no último índice divulgado pelo Instituto Nacional de Estudos e Pesquisas Educacionais Anísio Teixeira (Inep). É possível constatar que não estão havendo evoluções positivas nos resultados em relação as metas declaradas pelo Ministério da Educação do Brasil (MEC). Destacam-se os números que envolvem o ensino médio, os quais nos últimos censos estão abaixo da meta e estagnados a vários anos [Brasil 2018]. Diante deste cenário, este trabalho visa estudar o fenômeno da colaboração entre atores da comunidade escolar no entorno da atividade de planejamento de aulas. Busca-se construir conhecimento sobre a estrutura do trabalho colaborativo dos professores do ensino básico. Sendo assim, este conhecimento guiará a cocriação de um groupware que torne mais efetiva a prática docente, em particular, a atividade efetiva da prática colaborativa de planejamento de cenários de aprendizagem. Este projeto assume 
VIII Congresso Brasileiro de Informática na Educação (CBIE 2019)

Anais do VIII Workshop de Desafios da Computação aplicada à Educação (DesafIE 2019)

um paradigma pós-moderno, expresso pela realização de uma pesquisa antropológica e da utilização de técnicas da etnográfica digital como parte do processo de construção de conhecimento [Pink 2016]. Nesse sentido, emerge a questão central que norteia este projeto: Como um groupware promove o desenvolvimento efetivo da atividade de planejamento de aula no ensino médio num processo contínuo de co-design?

\section{Método}

A abordagem de co-design ocorrerá mediante a participação de atores do ambiente escolar nas sucessivas etapas da metodologia de design. Será adotada a abordagem de co-design da psicologia do trabalho, que orienta como a atividade e os sistemas de instrumentos implicados podem ser analisados com o professor, e como essa análise orienta a concepção de ferramentas para o exercício docente [Rabardel 1995].

\section{Objetivos}

O objetivo geral desta pesquisa é conceber um groupware que torne mais efetiva a atividade de planejamento de aula. Os objetivos específicos são: Analisar e descrever a prática coletiva de planejamento em termos dos sistemas de instrumentos que ocorre nessa atividade realizada por professores do ensino médio da educação básica; Cocriar um groupware de suporte à atividade colaborativa de planejamento de aulas com a participação de futuros usuários; Descrever a evolução dos sistemas de instrumentos que ocorre na atividade de planejamento colaborativo de aulas realizada por professores no nível básico de ensino médio ao longo do processo de cocriação do mesmo com futuros usuários; Avaliar a efetividade e a eficiência do groupware proposto enquanto mediador da prática colaborativa de planejamento de aula.

\section{Resultados esperados}

O presente trabalho almeja contribuir para uma melhor compreensão da atividade de planejamento de aula, com a intenção de influenciar a elaboração de sistema colaborativo de planejamento de aulas. Isso integra e contribui para práticas de ensino mais adequadas às exigências atuais da formação educacional brasileira.

\section{Referências}

Brasil (2018). Ministério da educação e cultura. saeb: Metodologia utilizada. SAEB Sistema Nacional de Avaliação da Educação Básica.

Nguyen, G. N. and Bower, M. (2018). Novice teacher technology-enhanced learning design practices: The case of the silent pedagogy. British Journal of Educational Technology, 49(6):1027-1043.

Pink, S. (2016). Digital ethnography. Innovative methods in media and communication research, pages 161-165.

Rabardel, P. (1995). Les hommes et les technologies; approche cognitive des instruments contemporains.

Rossitto, C. and Lampinen, A. (2018). Co-creating the workplace: Participatory efforts to enable individual work at the hoffice. Computer Supported Cooperative Work (CSCW), 27(3-6):947-982 . 